\title{
Results of patellectomy for osteoarthritis
}

\author{
J. M. Dinham \\ F.R.C.S.
}

\author{
P. R. FRENCH \\ F.R.C.S.
}

\section{Department of Orthopaedics, St George's Hospital, London}

\section{Summary}

Seventy-three knees which had undergone patellectomy for patello-femoral osteoarthritis are reviewed.

A possible mechanism of involvement of the tibiofemoral joint is described.

Patellectomy, when the disease is confined to the patello-femoral articulation, appears to be beneficial over a 5-year period. When arthritic changes are present in the tibio-femoral joint, patellectomy may be beneficial in about half the patients.

\section{Introduction}

The first operation on the patella was recorded (in the late nineteenth century) by Lister (1877).

Heineck (1909) discussed the techniques in vogue at that time for treatment of fractures of the patella. He concluded that patellectomy was indicated for compound frackures and in some comminuted fractures.

It was, however, only after Brooke (1937) reported that the patella was an unnecessary sesamoid bone which could be excised without altering the knee-joint mechanics, that patellectomy gained popularity.

O'Donoghue, Thompkins \& Hays (1952) reported good recovery of quadriceps strength following patellectomy. This was confirmed by West (1962) who followed up eighty-three patellectomies from 1 to 19 years. His series of operations had been performed for chondromalacia, advanced osteoarthritis, comminuted fractures and recurrent dislocations of the patella.

Smillie (1951) stated that patellectomy decreased the protection of the knee and eventually led to degenerative arthritis of the femoral condyles. Haxton (1945) and Cohn (1944) from their work on cadavers and experimental animals concluded that after patellectomy degeneration of the femoral condyles increased. Conversely, Geckeler \& Quaranta (1962) reported no progression of degenerative arthritis in knees after patellectomy. This was verified by Hoffer \& Schechter (1966) who reported seventy-five patellectomies in seventy patients. They found that patellectomy produced excellent results in cases of fracture or recurrent dislocation, and that patients with osteoarthritis were generally improved symptomatically, although movements improved in only nine out of thirty arthritic knees.

\section{Clinical material}

A series of patellectomies performed between the years 1949-66 for patello-femoral arthritis was assessed. The minimum follow-up period was 2 years.

All patients were personally examined by one of the authors. The symptoms, physical signs and radiographic changes at the time of operation and at the time of follow-up examination were recorded.

The number of patients examined was seventy (seventy-three knees). There were fifty-four women and sixteen men. One woman and two men had bis lateral operations.

The age of the patients at the time of operation is given in Fig. 1. The length of follow-up is given in? Fig. 2.

\section{Pre-operative assessment}

Prior to patellectomy all the patients had disabling symptoms which had been present from 1 month to 40 years. The average duration of symptoms was 2 years. The pre-operative symptoms are shown in Table 1.

Forty patients (forty knees) ascribed their symptoms to preceding trauma which had taken the form of a fall in twenty-seven $(68 \%)$, a knock in ten $(25 \%)$ and a twist in three (7\%).

Pre-operative radiographs disclosed patellofemoral arthritis in every knee. In eighteen knees $(25 \%)$ the tibio-femoral joint was radiographically normal. For convenience we shall call these Group I. The remaining fifty-five knees $(75 \%)$ showed

TABle 1. Pre-operative symptoms in seventythree knees

\begin{tabular}{lcc}
\hline & Number & $\%$ \\
\hline Pain & 73 & 100 \\
Swelling & 65 & 90 \\
Weakness and insecurity & 59 & 81 \\
Instability & 48 & 65 \\
Locking & 23 & 32 \\
Stiffness & 24 & 33 \\
\hline
\end{tabular}




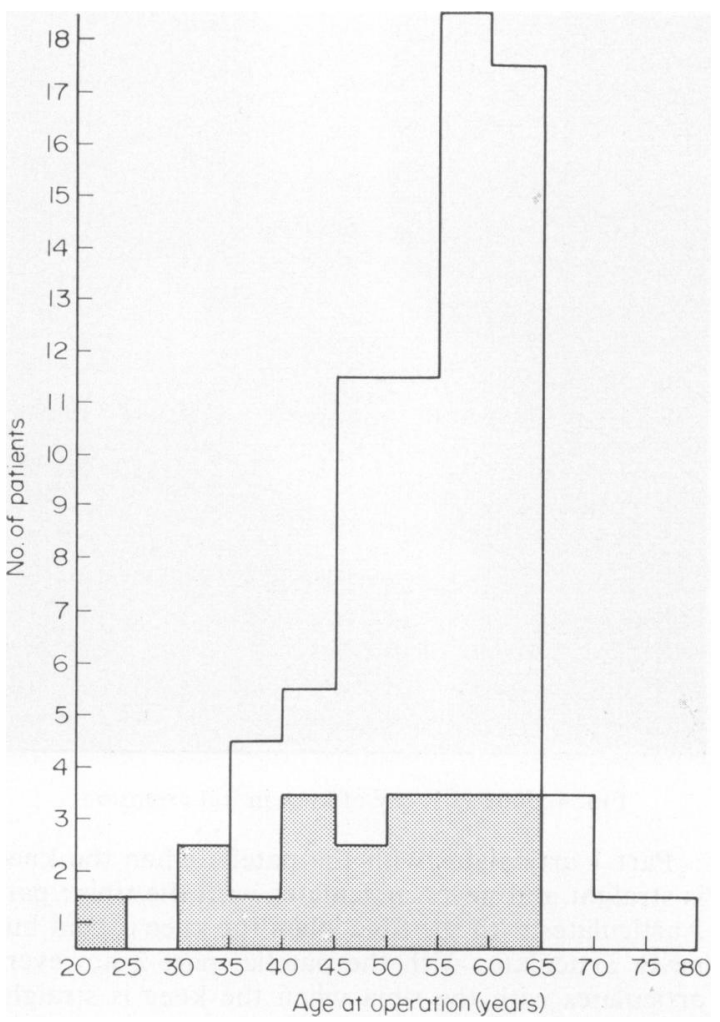

FIg. 1. Age of patients at time of patellectomy. Stippled columns, patients with radiographically normal tibiofemoral joints.

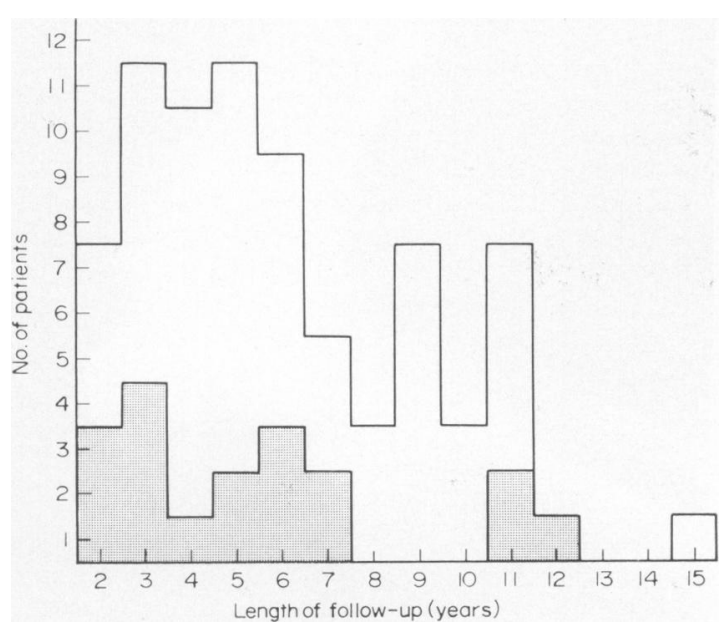

Fig. 2. Lengths of follow-up (mean 5 years). Stippled columns, patients with radiographically normal tibiofemoral joints. osteoarthritic changes varying from a decrease in joint space to marked degeneration. These we shall call Group II.

\section{Results}

Of the eighteen knees in Group I, four had undergone previous surgery. Of the fifty-five knees in Group II, eight had undergone previous surgery. The reasons for surgery are given in Table 2 .

TABLE 2. Reasons for previous surgery in seventy-three knees

\begin{tabular}{lcc}
\hline & Group I & Group II \\
\hline Medial meniscectomy & 1 & 4 \\
Lateral meniscectomy & 0 & 1 \\
Removal of loose body & 3 & 2 \\
Meniscectomy and loose body & 0 & 1 \\
Total & 4 & 8 \\
\hline
\end{tabular}

\section{Group I (eighteen knees)}

This group contained sixteen patients and included the two men with bilateral patellectomies.

Fourteen patients (sixteen knees) were pleased with their operation over a mean follow-up period of 5 years. Five had a slight ache and stiffness in the knee on rising in the morning which passed off after a few seconds. The radiographs of these sixteen knees showed normal tibio-femoral joints.

The remaining two patients (two knees) were only moderately pleased with their operation. They both had continuing pain, swelling, weakness and stiffness of the knee, and had lost movements. Radiographs of these knees showed a decrease in the medial joint space and minimal osteophyte formation. One woman aged 54 had had the medial meniscus removed 20 years previously.

\section{Group II (fifty-five knees)}

This group contained fifty-four patients (one woman bilateral).

Thirty-five patients (thirty-five knees) were pleased with their operation over a mean follow-up period of 6 years. Twelve patients (thirteen knees) were moderately pleased and the remaining seven dissatisfied.

Clinical assessment showed that a good result was obtained in twenty-six knees. In these, the symptoms, if any, were trivial, movements had increased and there was no radiological evidence of deterioration in the tibio-femoral osteoarthritis.

Ten knees had pain, swelling, insecurity and stiffness from time to time. Their movements had become worse or radiologically the degenerative changes had progressed.

The remaining nineteen knees had poor results. The patients had frequent disabling attacks of pain, swelling, weakness and insecurity. Their movements 
had decreased and radiographically the arthritis had progressed. Of these nineteen knees, one had been submitted to arthrodesis 3 years after patellectomy, five had unstable knees with valgus or varus deformity and a further patient had an unstable, ununited fracture of the femur and walked with the aid of a caliper and two sticks.

\section{Discussion}

It would appear that the patella, far from protecting the knee, is a source of morbidity. The commonest site in the knee joint for osteoarthritis is the patellofemoral articulation. Factors predisposing to this are old patellar fractures, osteochondritis, chondromalacia, subluxation or recurrent dislocation.

The extent of the patello-femoral articulation is little realized. If the lower end of the femur is viewed from its lateral aspect, the articular surface can be divided into three parts (see Fig. 3).

(a)

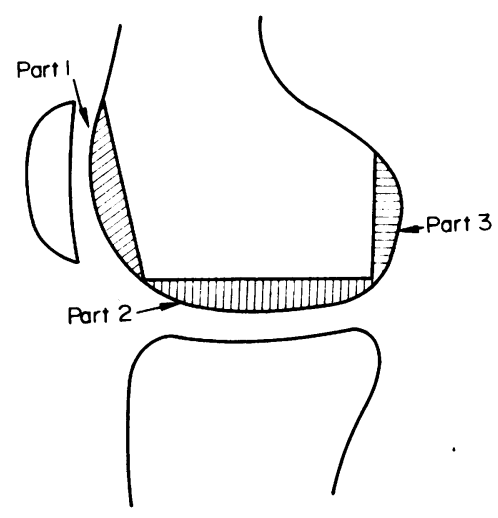

(b)

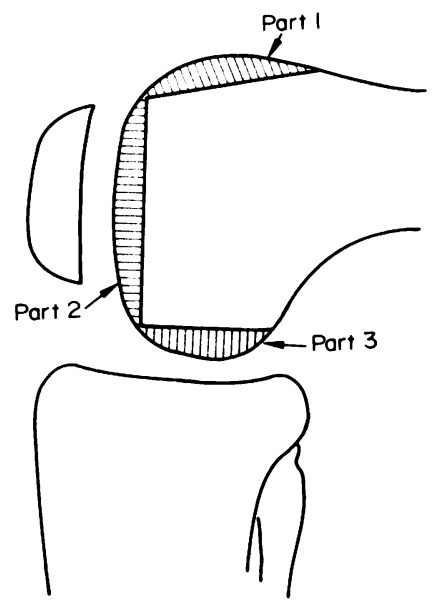

Fig. 3. The patello-femoral articulation. (a) Knee in full extension. (b) Knee in $90^{\circ}$ of flexion.

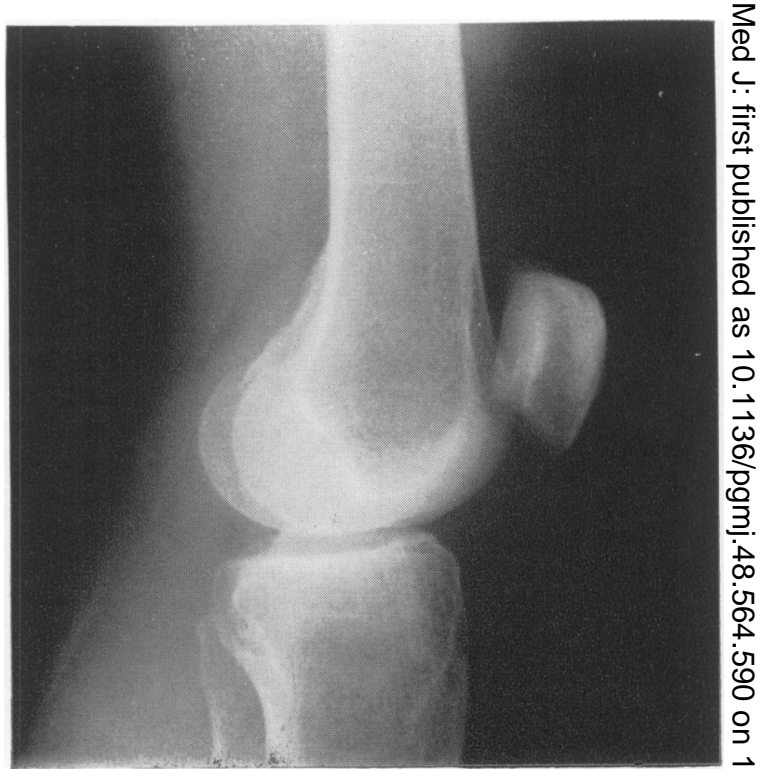

FIG. 4. Lateral X-ray of knee in full extension.

Part 1 articulates with the patella when the knee $\stackrel{\mathbb{D}}{\triangle}$ is straight and never articulates with the tibia; pagt $\overrightarrow{0}$ 3 articulates with the tibia when the knee is bent bi never articulates with the patella, part 2 howeves: articulates with the tibia when the knee is straig and with the patella when the knee is bent. This can be confirmed by radiographs (Figs. 4-6).

Patello-femoral wear at first affects part 1 , and with successive movement the worn patella can scour

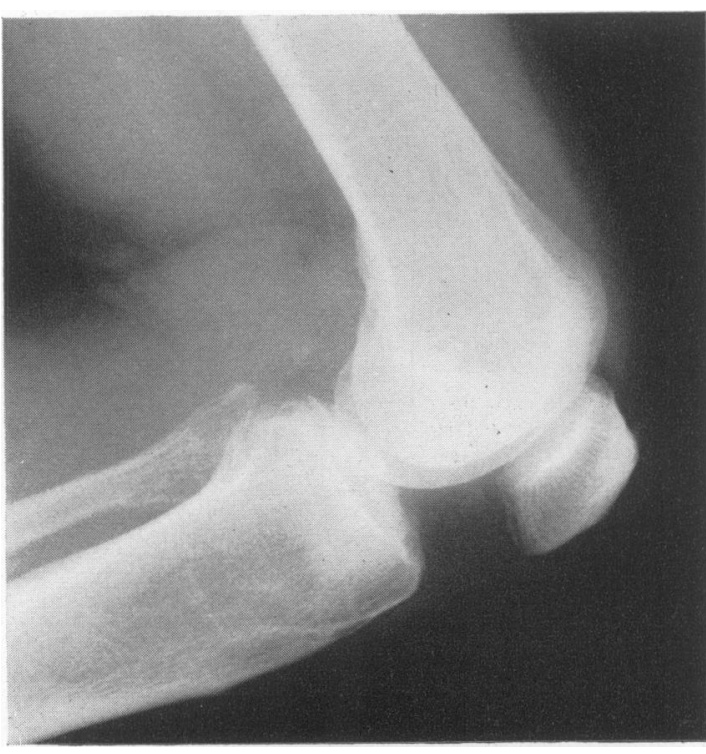

Fig. 5. Lateral X-ray of knee in $90^{\circ}$ flexion. 


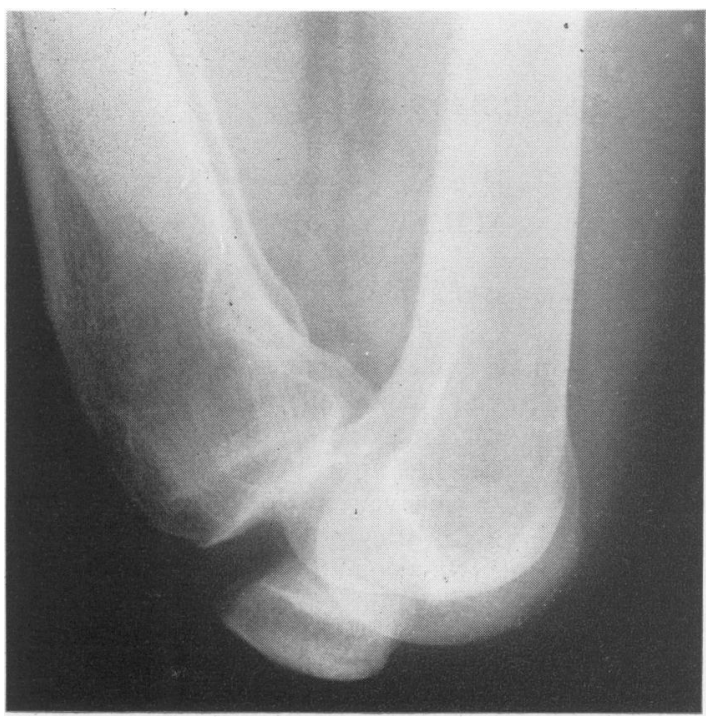

FIG. 6. Lateral X-ray of knee in full flexion.

part 2. This in turn can wear away the menisci and tibial table, causing tibio-femoral osteoarthritis. The last part of the knee to become worn is part 3 .

From this series, it would appear that, over a mean period of 5 years, patellectomy for patello-femoral arthritis before evidence of tibio-femoral arthritis is a good operation. Once cartilage damage has spread to involve the intermediate third of the femoral articular surface, tibio-femoral osteoarthritis develops. Patellectomy in these circumstances appears to be beneficial in about half of the knees so affected.

\section{References}

BRoOKE, R. (1937) The treatment of fractured patella by excision. British Journal of Surgery, 24, 733.

CoHN, B.N.E. (1944) Total and partial patellectomy and experimental study. Surgery, Gynaecology and Obstetrics, 79, 526.

Duthie, H.L. \& Hutchinson, J.R. (1958) The results of partial and total excision of the patella. Journal of Bone and Joint Surgery, 40B, 75.

GeCkeler, E.O. \& Quaranta, A.V. (1962) Patellectomy for degenerative arthritis of the knee. Journal of Bone and Joint Surgery, 44A, 1109.

Haxton, H. (1945) The function of the patella and the effects of its excision. Surgery, Gynaecology and Obstetrics, 80, 389.

HeineCK, A.P. (1909) The modern operative treatment of fractures of the patella. Surgery, Gynaecology and $\mathrm{Ob}$ stetrics, 9, 177.

HOFFER, M.M. \& SCHEChTER, D.E. (1966) Results of seventyfive patellectomies in seventy patients. American Journal of Surgery, 3, 645.

LISTER, J. (1877) Reports of medical and surgical practice in the hospitals and asylums of Great Britain. Mr Lister's wards: a new operation for fracture of the patella. British Medical Journal, 2, 850.

O'Donoghue, D.H., Thompkins, F. \& Hays, M.B. (1952) Strength of the quadriceps function after patellectomy. Western Journal of Surgery, 60, 159.

SmILlIE, I.S. (1951) Injuries to the Knee Joint, 2nd Edn, p. 230. Livingstone, London.

WEST, F.E. (1962) End results of patellectomy. Journal of Bone and Joint Surgery, 44A, 1089. 